\title{
EOPs: Abordaje conservador de los pacientes con otitis media aguda
}

\author{
Conservative management of patients with acute otitis media
}

Mariela Franchini* y Andrés D’lppolito**

\begin{abstract}
Resumen
A partir de la descripción de un caso de otitis media aguda (OMA) infantil se discuten las principales estrategias de abordaje de estos pacientes, especialmente el punto relacionado con evidencia que avala la prescripción inmediata y/o diferida de antibióticos.

Se concluye que en los pacientes de bajo riesgo -sintomatología no severa, ausencia de comorbilidades y seguimiento asegurado a las 48 horas- existe suficiente evidencia para avalar el tratamiento sintomático inicial sin prescripción de antibióticos, esperando la resolución espontánea de la enfermedad, que ocurre en más del $80 \%$ de los pacientes. Al final de este EOP, resumimos la Guía Inglesa para la prescripción de antibióticos para las infecciones autolimitadas del tracto respiratorio publicada en 2008.

\section{Abstract}

After the description of a case of acute otitis media (AOM) in a child, the author discuss the most used management strategies for this group of patients, stressing the evidence about immediate or postponed antibiotic prescription. She concludes that there is enough evidence to support initial symptomatic treatment without antibiotic prescription in low risk population non severe symptoms, no co-morbilities and accessibility for another control visit two days later- waiting spontaneous resolution of the illness, what happens in more than $80 \%$ of patients.

At the end of this article we summarize the Guide from United Kingdom about prescribing antibiotics for self-limiting respiratory tract infections in adults and children in primary care, published during 2008.
\end{abstract}

Palabras clave: otitis media aguda, antibióticos, tratamiento sintomático. Key words: acute otitis media, antibiotics, symptomatic treatment.

Franchini M y D'lppolito A. Abordaje conservador de los pacientes con otitis media aguda. Evid. Actual. Práct. Ambul; 12(1):33-34, Ene-Mar 2009.

\section{Caso clínico}

Paciente de dos años de edad con otalgia moderada de tres horas de evolución y 39 grados de temperatura. Al examen físico lo encuentra irritable y sin otras particularidades, salvo una membrana timpánica eritematosa y con disminución de su movilidad en la otoscopía neumática.

De acuerdo a la presentación clínica y el examen otoscópico, el médico decide iniciar tratamiento con analgésicos/antipiréticos y reevaluar al paciente en 48 horas.

\section{Pregunta que generó el caso}

En los pacientes de dos años de edad con diagnóstico de otitis media aguda, el tratamiento inicial con antibióticos, comparado con el tratamiento analgésico, ¿mejorará la evolución clínica de la misma?

\section{Búsqueda bibliográfica}

Se utilizaron en castellano y en inglés las siguientes palabras para responder la pregunta "otitis media aguda", "tratamiento", "antibióticos" y "estudios controlados aleatorizados".

La búsqueda fue realizada en Pubmed.

\section{Datos sobre la otitis media aguda}

Se denomina otitis media aguda (OMA) a la inflamación e infección de la mucosa del oído medio de comienzo agudo y con una duración menor de tres semanas.

Las vías clásicas de infección son la tubárica y la canalicular a través del conducto auditivo externo -cuando existe perforación previa de la membrana timpánica- siendo la etiología habitualmente bacteriana y los gérmenes más frecuentemente involucrados, S. pneumoniae y H.influenzae.

La disfunción de la trompa de Eustaquio sería el factor más importante en la patogénesis de la enfermedad del oído medio, ya que puede conducir al desarrollo de contenido de líquido (infectado o nó) secundario a reflujo, aspiración o insuflación de bacterias desde la nasofaringe hacia el oído medio. La obstrucción tubaria funcional es frecuente en menores de tres años y consecutiva a alteraciones funcionales del cartílago y la musculatura; mientras que la obstrucción mecánica puede ser extrínseca (ej. tumor o masa adenoidea) o intrínseca (ej. inflamación crónica de causa alérgica).

Algunos virus (Virus sincicial respiratorio, Adenovirus, Rinovirus e Influenza) favorecen el desarrollo y la persistencia de los síntomas de OMA.

Enumeramos a continuación algunos factores de riesgo para desarrollar recurrencia de OMA:

1. Un primer episodio de OMA antes del año de vida.

2. Una vivienda hacinada o la concurrencia a guarderías.

3. El humo de tabaco ambiental, por ejemplo por convivencia con fumadores.

4. Factores hereditarios.

5. La ausencia de lactancia materna durante los primeros tres meses.

6. La alimentación en decúbito dorsal.

7. La práctica de natación (debe valorarse riesgo versus beneficio en niños pequeños).

8. El sexo masculino.

9. Las alteraciones de la inmunidad.

El diagnóstico de otitis media se realiza sobre la base de los síntomas clínicos y de los signos aportados por la otoscopía de luz y la neumatoscopía e incluye:

- Manifestaciones clínicas de afección sistémica como llanto, irritabilidad, cefalea, anorexia y/o fiebre.

- Manifestaciones clínicas de afección local como otalgia u otorrea proveniente del oído medio; abombamiento, opacidad o fuerte congestión (aspecto claramente rojo) de la membrana timpánica o líquido amarillo por detrás de la misma, y/o disminución de la movilidad de la membrana timpánica documentada por neumatoscopía.

Dentro de las complicaciones infrecuentes de la OMA podemos mencionar las intratemporales como la mastoiditis, la laberintitis, la pe-trositis y la parálisis facial; y las intracraniales como el absceso extradural, el absceso subdural, el absceso cerebral, la meningitis y la tromboflebitis del seno sigmoideo. 
Absceso extradural. En general, se acepta que en los niños mayores de seis meses y menores de dos años con otitis leve a moderada, sin historia de recurrencia de OMA, podría diferirse inicialmente el uso de antibióticos, utilizándolos ante ausencia de mejoría clínica entre las 48 y 72 horas de tratamiento. Esta conducta podría hacer disminuir el uso indiscriminado de antibióticos y consecuentemente, la preo-cupante elevación de las tasas de resistencia antibiótica bacteria-na y la incidencia de efectos adversos de los mismos. Vale además aclarar que la mayoría de las guías de práctica clínica recomiendan la indicación inicial de tratamiento antibiótico en los niños con menos de seis meses de edad.

\section{Resumen de la evidencia}

Glasziou P y col. Antibiotics for acute otitis media in children. Cochrane Review. In: The Cochrane Library, Issue 3, 2003.

Este trabajo muestra una revisión sistemática de estudios aleatorizados de alta calidad metodológica que compararon el uso de antibióticos versus placebo en niños con OMA. Los autores revisaron la biblioteca Cochrane, Medline, Current Contents, y la bibliografía de los artículos, desde 1958 a 1999. De un total de diez estudios, seleccionaron siete que contenían resultados relevantes, con un total de 2202 niños. Los principales resultados hallados fueron los siguientes:

A las 24 horas de haber iniciado el tratamiento, dos tercios de los niños de ambos grupos dejaron de manifestar dolor. Un $80 \%$ de los pacientes del grupo control presentó reducción espontánea del dolor entre el segundo y el séptimo día. La reducción del dolor atribuible al uso de antibiótico fue cercana a $7 \%$, lo que implica que sería necesario tratar a 17 niños para prevenir que uno de ellos tenga dolor después del segundo día de tratamiento. Progresión de los síntomas y efectos adversos: en el grupo tratado se encontró una tendencia no estadísticamente significativa hacia un menor desarrollo de otitis contralateral, mayor incidencia de efectos adversos como náuseas, diarrea y erupción. No hubo diferencia significativa en el número de recurrencias entre ambos grupos y occurrieron pocas complicaciones serias en ambos grupos. El estudio concluyó que, si bien el uso de antibióticos acorta el curso de la OMA en niños, la mayoría de los casos se resolverán espontáneamente sin complicaciones asociadas. Este beneficio debería cotejarse con la posibilidad de reacciones adversas asociadas a los mismos. El uso de antibióticos podría tener una función importante en la reducción del riesgo de mastoiditis, en aquellas poblaciones donde esta entidad es más frecuente. Por lo tanto, en el manejo de los pacientes con OMA debería enfatizarse el uso de una adecuada analgesia, limitando el uso de antibióticos.

A continuación se resume un ensayo clínico publicado luego de la revisión sistemática.

David M y col. Wait-and-See Prescription for the Treatment of Acute Otitis Media. JAMA. 2006; Vol. 296 No. 10:1235-1241.

El presente ensayo clínico aleatorizado y controlado tuvo como objetivo determinar si la estrategia de abordaje de la OMA utilizando la táctica de "esperar y ver" reduce significativamente el uso de antibióticos cuando se la compara con la "prescripción estándar de antibióticos", y evaluar los efectos de ambas en los síntomas clínicos y en los efectos adversos relacionados con los antibióticos.Participaron del estudio, niños de seis meses a 12 años de edad reclutados entre julio de 2004 y julio de 2005, a quienes se les había realizado el diagnóstico de otitis media aguda (OMA) en el departamento de urgencias pediátricas del Yale-New Haven Hospital.

A los padres de todos los participantes $(n=283)$ se les entregó una prescripción escrita de los antibióticos. Esta prescripción expiraba tres días después de la visita del niño al departamento de urgencias pediátricas, y los niños fueron asignados aleatoriamente a recibir dos tipos de tratamiento:

a- "Esperar y ver" antes de cumplir la prescripción de antibióti$\cos (n=138)$ lo que significaba que los padres no administrarían los antibióticos prescritos salvo que el niño no mejorase o empeorase durante las 48 horas posteriores a la visita.

b- "Prescripción estándar de antibióticos" $(n=145)$ lo que significaba que los padres administrarían los antibióticos prescritos inmediatamente después de la visita al departamento de urgencias pediátricas.

Todos los participantes recibieron frascos de ibuprofeno en una suspensión de $100 \mathrm{mg}$ en cinco mililitros, y gotas de un analgésico otológico para ser aplicado en la casa.

Los resultados principales del estudio fueron contundentes. Sólo el $13 \%$ de los padres de los pacientes asignados a la estrategia "esperar y ver" administraron los antibióticos al niño vs. el $62 \%$ de los del grupo grupo "prescripción estándar". No hubo diferencias estadísticamente significativas entre los dos grupos en cuanto a la frecuencia de fiebre, dolor de oídos (otalgia) o visitas no programadas. Sin embargo, en el grupo de "esperar y ver" tanto la presencia de fiebre y la de otalgia se asociaron con el cumplimiento de la prescripción de antibióticos. Según los autores, la táctica de "esperar y ver" para el manejo de la OMA en niños que acuden a los servicios de urgencias pediátricas, reduce el uso innecesario de antibióticos, y puede ser una alternativa al uso rutinario de antibióticos.

\section{Conclusiones}

La evolución habitual de la OMA suele ser hacia su resolución espontánea, con una franca mejoría del dolor en el $80 \%$ de los pacientes durante las primeras 48 horas, independientemente de cuál haya sido el tratamiento implementado.

Los estudios que hemos resumido han demostrado que el tratamiento antibiótico no tiene influencia sobre la resolución del dolor antes de las 24 horas de iniciado el cuadro, aunque entre el segundo y el séptimo día de evolución -período durante el cual sólo el $20 \%$ de los niños continúa con dolor- el uso de antibióticos reduce un $40 \%$ la probabilidad de otalgia. Esto implica que el verdadero beneficio atribuible al uso de antibiótico para reducir el riesgo de persistencia de dolor luego de las primeras $48 \mathrm{~h}$ es $7 \%$, siendo preciso tratar a 15 niños para evitar que uno continúe con dolor más allá de los dos días de comenzado el cuadro. Esta información debería sopesarse con el riesgo individual de efectos adversos a los antibióticos y con el riesgo social de que se produzca resistencias bacterianas. Consideramos, por lo tanto que en atención primaria debería reducirse el uso de antibióticos, empleándolos únicamente cuando no tenga lugar una curación espontánea. En general, se recomienda un periodo de observación y analgesia de 72 horas; y si pasado este período el cuadro no se resuelve, iniciar la administración de antibióticos. Sin embargo, la mayoría de las guías de práctica clínica recomienda la indicación inicial de antibióticos si el niño es menor de seis meses, ante más de $3^{\circ} \mathrm{C}$ de temperatura o sintomatología moderada o severa (otalgia) y en los pacientes en quienes sea difícil asegurarse el seguimiento.

Información adicional; ver Guía de Práctica Clínica, página 39.

Recibido el 11/08 y aceptado el 02/09 